\title{
REDES COMUNICACIONALES Y PROCESOS IDENTITARIOS ENTRE LOS QOM ASENTADOS EN LA CIUDAD DE ROSARIO ( ARGENTINA)
}

\author{
Margot BIGOT ${ }^{1}$
}

\section{Resumen}

Las migraciones de la población qom desde los lugares de origen hacia la ciudad de Rosario, comenzaron en la década del 60 y continúan hasta la actualidad. En este trabajo se tratarán las redes comunicacionales de los qom, sus representaciones y prácticas lingüísticas en vinculación con los procesos identitarios.

Palabras clave: - redes comunicacionales - representaciones y prácticas lingüísticasprocesos identitarios

\section{Résumé.}

Les migrations des populations qom depuis leurs lieux d'origine vers la ville de Rosario ont commencée dès les années 60', et se poursuivent jusqu'à l'heure actuelle. Ce dossier concerne les réseaux de communications des qom, leurs répresentations et pratiques linguistiques, par rapport aux processus identitaires.

Mots clé: -réseaux de communications - répresentations et pratiques linguistiques processus idéntitaires.

\begin{abstract}
.
Migrations of qom populations from their original locations to the city of Rosario started in 1960, and continued all over these years just to our days. This paper deal with qom's communicational networks, their representations and linguistic practices in a liaison with identitary processes.
\end{abstract}

Keywords: -communicational networks - linguistic practices and representations identitary processes.

\section{Introducción}

Las migraciones de la población qom desde los lugares de origen (localidades urbanas y rurales de la provincia del Chaco) hacia la ciudad de Rosario, comenzaron en la década del 60 y continúan hasta la actualidad. Se trata de personas en una situación de pobreza extrema excluidas del sistema político - social. De esta manera se vienen conformando distintos asentamientos en los que la vigencia de hábitos culturales y patrones de

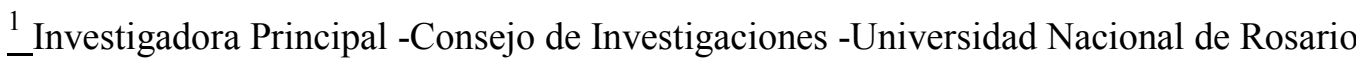

Fecha de recepción del artículo: Agosto 2015

Fecha de evaluación: Noviembre 2015
} 
conducta tradicionales dependen del grado de integración de cada grupo a las distintas redes comunicacionales en las cuales participa y su incidencia en las representaciones sociolingüísticas.

En este contexto, de relaciones sociales desiguales, se elaboran "procesos identitarios" en función de la situación de interacción, es decir en función de diferentes determinaciones (socio-históricas, culturales, psicológicos) de esa situación. Las actitudes y conductas, el sistema de creencias, el manejo de la lengua qom y la competencia en el español rioplatense no es homogéneo, aún al interior de cada asentamiento.

Diferenciándonos de las posturas que vinculan la "identidad étnica" a una idea de la cultura como esencia, en las que "identidad" connota inmutabilidad, cristalización, el concepto que utilizamos destaca el carácter procesual de la identidad en las complejas dinámicas culturales que se generan en contextos de contacto lingüístico cultural en condiciones de desigualdad. Hablamos de "procesos étnicos identitarios" (BigotRodríguez-Vázquez 1991 - Vázquez 2000) como procesos diacrónicos y diatópicos, condicionados por factores psico-sociales, lingüístico-culturales, e históricos.

Entre los grupos qom los procesos identitarios manifiestan matices diferenciales, aún en un mismo asentamiento, por condicionamientos socio-históricos, lugares de procedencia, parcialidades de pertenencia, a los que se agregan variables generadas localmente: tiempo de residencia en el asentamiento frecuencia de la interacción con sectores de la sociedad regional, sincretismo cultural. No obstante la lengua (que definimos como conjunto de variedades) qom (toba), es reconocida como cohesionador étnico y símbolo identitario transversal

La interdependencia entre las funciones lingüísticas de "comunicar" (carácter social colectivo- de la práctica lingüística) y de "significar" (la cultura, las prácticas sociales, la cosmovisión de un grupo $)^{2}$ hace que la intercomunicación instituya un mundo común de significaciones, ubicando a la lengua como medio por excelencia con el que las personas, estableciendo sus relaciones, se constituyen en sociedades diferenciadas: la lengua contribuye a sustentar la cohesión grupal, a la vez que pone de relieve la diferenciación extragrupal. Y es este poder cohesivo y diferenciador de la lengua el que cimenta su función de marcador identitario.

\section{Red comunicacional toba}

El concepto de "red comunicacional" (Bigot 2007) más abarcativo que el de "comunidad" (en sus versiones lingüística, de comunicación etc., centradas en lo lingüístico), resulta más operativo para aplicar a la situación de relaciones intraétnicas (entre grupos tobas) y socioétnicas (entre grupos tobas y segmentos de la sociedad dominante) ya que permite tratar correlacionadamente interactuación social / uso de las lenguas (qom-español), y diferenciar ámbitos socio-espaciales "contextos de comunicación".

La "red comunicacional" abarca el conjunto de interacciones lingüísticas que se establecen en los "contextos de comunicación". Estos "contextos de comunicación", a los que se vincula el uso de una u otra lengua: qom y español, son los ámbitos de relaciones sociales en los que están insertos los indígenas qom de los asentamientos. El

\footnotetext{
${ }^{2}$ los procesos de comunicación se llevan a cabo sobre la base de sistemas de significación y todo sistema de significación tiene por fin la comunicación (Eco, 1990)
} 
concepto de comunicación implica que se comparte al menos un conjunto de conocimientos, entre ellos una lengua (conjunto de variedades) y condiciones de uso.

Los siguientes contextos configuran la red:

- contexto de comunicación intraétnico "local" y "supralocal"

- $\quad$ "local" (entre los residentes de un mismo asentamiento, y entre residentes de distintos asentamientos de una misma localidad)

- "supralocal" (entre grupos asentados en las grandes ciudades con grupos qom de las localidades de procedencia en la provincia del Chaco,

En este contexto la comunicación se realiza casi exclusivamente en lengua qom; en el contexto "local", en distintas variedades de la lengua qom, y en el "supralocal" en la misma variedad.

- un contexto socio-étnico, en el que la comunicación con los segmentos de la sociedad regional/nacional se realiza en español

- Un contexto interétnico ( entre representantes indígenas de distintas etnias que participan en movimientos indianistas y tienen como lengua vehicular el español)

Aunque los grupos qom son, como hemos señalado, relativamente heterogéneos, pertenecen a distintas parcialidades, y son hablantes de distintas variedades de la lengua qom, no obstante, por ser estas variedades mutuamente inteligibles, la lengua (sistema de comunicación y de significación) constituye un factor de cohesión étnica transversal a la heterogeneidad de los grupos y a los procesos identitarios. En este sentido el contexto de comunicación intraétnico puede ser definido como "comunidad etnolingüística" concepto que, en base a la relación lengua-cultura-sociedad, implica que los distintos grupos que participan de ella comparten hábitos de comunicación y simbolización lingüística en la lengua nativa, y las intersecciones (de distinta amplitud) de conjuntos de pautas de comportamiento, creencias, valores.

El contexto de comunicación intraénico supralocal propicia la tendencia a reproducir en los asentamientos urbanos las pautas culturales y sociolingüísticas de los lugares de origen. Entre los grupos rurales hay un mayor porcentaje de monolingües qom (los contactos con segmentos de la sociedad dominante tienen una menor frecuencia) y el uso de la lengua qom es exclusivo en la comunicación cotidiana. Si bien las ciudades son generalmente los espacios donde el contacto de lenguas favorece la transferencia a la lengua dominante, entre los indígenas Qom, las constantes migraciones: el ingreso de nuevas familias - en muchos casos monolingües qom- a los asentamientos de las ciudades, y los viajes periódicos que con distintos motivos realizan los miembros de familias ya asentadas (desplazamientos que constituyen una readaptación de los aspectos migratorios de la cultura original) trasladan a la ciudad los hábitos lingüísticoculturales de los lugares de origen. La lengua qom se utiliza en distintos dominios (familiar, grupal, religioso) de la comunicación intraétnica y se trasmite a las nuevas generaciones, neutralizando en parte los efectos de la urbanización.

El contexto de comunicación socioétnico está marcado por relaciones "desiguales" y "asimétricas". "Desiguales" entre una sociedad política y económicamente dominante (cuyos sistemas educativo, jurídico, de salud, etc. están diseñados en vistas a la 
población mayoritaria) y los indígenas qom subalternizados o excluidos. "Asimétricas" entre la minoría qom y la sociedad mayoritaria-hegemónica que ejerce una fuerte dominancia (presión no deliberada o dominación simbólica para Bourdieu (1985) por su prestigio lingüístico y cultural. El contexto de comunicación socio-étnico impone necesariamente a los qom el uso instrumental de la lengua dominante, el español

El contexto de comunicación interétnico es muy restringido, refiere a las relaciones que dirigentes de diferentes grupos étnicos indígenas, (hablantes de distintas lenguas) establecen para el diseño conjunto de estrategias etnopolíticas, tanto a nivel nacional como internacional, en las que el español se jerarquiza por ser la lengua vehicular.

El resultado de la red comunicacional es una situación sociolingüística de bilingüismo diglósico. (la lengua qom se utiliza en la comunicación intraétnica y el español con segmentos de la sociedad regional), correlacionado con los procesos de síncresis cultural (Bigot 1999) y con los procesos identitarios.

\section{Representaciones, actitudes, y prácticas sociolingüísticas}

Desde perspectivas que consideran los condicionamientos (socio-históricos) de reproducción y utilización de las lenguas, se ha advertido la relación entre "representaciones" y "prácticas" lingüísticas. Las representaciones de los hablantes acerca de las lenguas, inciden en la dinámica de las situaciones lingüísticas, y son, por lo tanto, particularmente relevantes para el análisis del funcionamiento diglósico (repartición funcional de las lenguas, papel de la(s) lengua(s) en los procesos identitarios), en situaciones de relaciones desiguales entre grupos minoritarios y sociedad dominante.

P. Dumont - B.Maurer (1995), ponen de relieve la relación entre representaciones y prácticas, expresan que no se trata de una relación unidireccional (las representaciones concebidas como reflejo de las prácticas) sino que por el contrario hay una determinación recíproca. La relación entre los dos términos es dialéctica, se determinan mutuamente: las representaciones, surgidas de las prácticas, en acción de retorno las informan y las orientan. Establecen una distinción entre "representaciones lingüísticas" relacionadas con las maneras de hablar (que manifiestan aspectos metalingüísticos) y "representaciones sociolingüísticas" que refieren a las formas en que los hablantes perciben, a nivel individual y colectivo, sus prácticas sociolingüísticas, estatus de las lenguas, funciones, papel identitario.

\subsection{Las representaciones sociolingüísticas de los qom}

El "discurso epilingüístico", definido como discurso de los locutores sobre las lenguas y lo que simbolizan en el plano cultural, social y psicológico (March 1996) es una vía privilegiada para el análisis de las representaciones sociolingüísticas. El relevamiento de dichos discursos entre los indígenas qom, nos proporcionó los datos necesarios para el análisis.

Los contextos de comunicación que configuran la red comunicacional qom, es decir los distintos ámbitos de relaciones, intraétnico y socioétnico, en los que participan los indígenas qom tienen una incidencia relevante en la formación de las representaciones sociolingüísticas. Estas se construyen de una manera compleja, a través de la vinculación de aspectos afectivos y cognitivos que se generan en el entorno sociocultural. 


\subsubsection{Aspectos afectivos: la lengua como marcador identitario}

Según los datos arrojados por la encuesta epilingüística realizada en los asentamientos tobas de Empalme Graneros (Av. Travesía y Av. Génova) y Los Pumitas (Campbell y Av. Ludueña) de la ciudad de Rosario, los indígenas qom se autoadscriben como pertenecientes a una unidad étnica "qoomi nam qom" hablantes de la "qom l'aqtaqa" (lengua "qom"). La significación de "qoomi" (en castellano "nosotros") equivale, en el "contexto de comunicación socioétnica", a una primera persona plural exclusiva que, en su extensión máxima: "yo + los otros miembros de la parcialidad + las otras parcialidades "qom", funciona (y también el posesor correspondiente) como marcador identitario del conjunto de parcialidades qom -hablantes de distintas variedades de la lengua qom- trazando así una frontera étnica.

Hay consenso sobre la delimitación de la entidad "lengua qom" comprensiva de las variedades habladas por las distintas parcialidades, que por ser mutuamente inteligibles posicionan a la lengua como un factor de cohesión étnica: hablar la lengua "qom" es considerado inherente a la pertenencia étnica: la lengua "qom" se percibe como un marcador identitario transversal.

Los aspectos afectivos de las representaciones sociolingüísticas, ligados al contexto intraétnico de comunicación, predisponen a los hablantes a percibir la lengua qom como un "valor fundamental", es decir como un componente central de la cultura que actúa como valor de identificación grupal (J.J.Smolicz 1982)

\subsubsection{Aspectos cognitivos}

Los aspectos cognitivos, permean una percepción dicotómica en la evaluación de la lengua nativa:

- La vehiculización de informaciones, opiniones, y acciones concretas de la sociedad de contacto -estigmatización, discriminación, exclusión- promueven una apreciación negativa de la lengua qom en cuanto se reconoce el límite de sus funciones, y el manejo del castellano se impone necesariamente para interactuar con la sociedad dominante.

- La participación en movimientos indianistas y las estrategias etnopolíticas (BigotRodríguez- Vázquez 1995) generadas por líderes indígenas locales y sus logros reivindicativos condicionan una valoración positiva de la lengua qom.

\section{Conclusiones}

El sistema de representaciones contradictorias - valoración positiva/ negativa- de la lengua minoritaria o minorizada aparece como característico en las situaciones de diglosia conflictual que se generan en contextos de relaciones desiguales (Gatdy, $\mathrm{Ph}$ Lafont, R 1981; Boyer, H 1997). Entre los qom de los asentamientos de Empalme Graneros y los Pumitas las representaciones sociolingüísticas contradictorias de la lengua nativa son notorias en el plano cognitivo que está condicionado y manipulado por las múltiples formas en que la dominación se manifiesta (valoración negativa), pero también por las estrategias etnopolíticas que los indígenas elaboran como réplica a esa situación (valoración positiva).

Los aspectos afectivos ligados a la pertenencia étnica y los aspectos cognitivos ligados a las estrategias etnopolíticas que han concientizado a los indígenas sobre sus derechos lingüísticos y culturales, impulsan actitudes positivas hacia la lengua propia, 
neutralizando en parte su posicionamiento desfavorable en relación a la lengua dominante.

La tendencia que marcan las representaciones sociolingüísticas es coherente con las prácticas sociolingüísticas actuales en los pertinentes contextos de comunicación -uso intraétnico y transmisión a las nuevas generaciones de la lengua qom- y con la práctica lingüística que, en los procesos actuales de sincretismo cultural, mantiene la funcionalidad de la lengua qom -prácticas que se inscriben en estrategias de resistencia etnolingüística- a la vez que el manejo del castellano se aprecia como necesario (Bigot 1998).

Considerando la relación entre contextos de comunicación, representaciones sociolingüísticas y prácticas lingüísticas se extrae que las estrategias de resistencia etnolingüística y las estrategias etnopolíticas procesan las tensiones -que genera el contexto diglósico lengua dominante /dominada- entre la valoración positiva de la lengua qom y las necesidades del uso del castellano en la vida cotidiana urbana, creando condiciones para el mantenimiento de la lengua, si bien el número de monolingües qom disminuye y el bilingüismo mayoritario de los qom emerge como constitutivo en los procesos étnicos identitarios en los asentamientos de Empalme Graneros y Los Pumitas.

\section{Bibliografía}

BIGOT, M (1998):"La vitalidad etnolingüística de un grupo minoritario indígena en contexto de relaciones socio-étnicas" - Papeles de Trabajo $N^{o} 7$ - Revista del Centro Interdisciplinario de Ciencias Etnolingüísticas y Antropológico Sociales - Universidad Nacional de Rosario

BIGOT, M (1999): "Oralidad y escritura " en En la encrucijada del lenguaje: oralidad, lectura y escritura - Autores: Bigot - Fernández- Freidenberg - Hachén - Jitrik Solana- Centro de estudios de adquisición del lenguaje - Facultad de Humanidades y Artes - UNR - Rosario.

BIGOT , Margot (2007) "Los aborígenes "qom” en Rosario. Contacto lingüísticocultural, bilingüismo, diglosia y vitalidad etnolingüística en grupos aborígenes "qom" (tobas) asentados en Rosario"- UNR Editora -ISBN 978-950-673-607-1 -

BIGOT,M-RODRIGUES, HG-VÁSQUEZ (1995): "Construcción de liderazgos y de estrategias etnopolíticas en un grupo de familias tobas asentadas en la ciudad de Rosario" - Papeles de Trabajo $N^{\circ} 4$ - UNR, Rosario.

BIGOT, M - RODRIGUEZ, G - VAZQUEZ, H (1991) "Los aborígenes qom (Toba): situación socio-cultural procesos étnicos identitarios. Análisis de los asentamientos de la ciudad de Rosario" - América Indígena, enero- marzo - Vol. LI, $N^{o} 1$ - publicación del Instituto Indigenista Interamericano - México, .

BOURDIEU, P (1985): ¿Qué significa hablar? - Akal - España 
BOYER, H (1997): "Conflit d'usages, conflit d'images" en Plurilinguisme: "contact" ou "conflit" de langues? H.Boyer (ed.) - L'Harmattan - Francia

GARDY, Ph - LAFONT, R (1981) : "La diglossie comme conflit: l'exemple occitan", Langages $N^{0} 61$ - Larousse, París.

DUMONT, P - MAURER, B (1995): Sociolinguistique du français en Afrique francophone- Edicef - Francia

ECO,H (1990):Semiótica y Filosofía del lenguaje.Ed. LUMEN, Barcelona

MARCH, C (1996): Le discours des mères martiniquaises - L'Harmattan - París

SMOLICZ, J (1982) : "Valeurs fondamentales et identité culturelle" en Identité culturelle:approches méthodologiques - CIRB - Canadá

VAZQUEZ, H (2000): Procesos identitarios y exclusion socio-cultural - Editorial BIBLOS- Bs. As 